\title{
Optimization of Energy Consumption of Broiler Production Farms using Data Envelopment Analysis Approach
}

\author{
Mohammad Davoud Heidari (Corresponding author) \\ MSC student in Department of Agricultural Machinery Engineering \\ Faculty of Agricultural Engineering and Technology, University of Tehran, Karaj, Iran \\ Tel: 98-261-280-1038Ｅ-mail: mdheidari@ut.ac.ir \\ Mahmoud Omid \\ Professor in Department of Agricultural Machinery Engineering \\ Faculty of Agricultural Engineering and Technology, University of Tehran, Karaj, Iran \\ Tel: 98-261-280-1038 E-mail: omid@ut.ac.ir
}

Asadollah Akram

Professor in Department of Agricultural Machinery Engineering

Faculty of Agricultural Engineering and Technology, University of Tehran, Karaj, Iran

Tel: 98-261-280-1038Ｅ-mail: aakram@ut.ac.ir

Received: March 6, 2011

Accepted: April 24, 2011

doi:10.5539/mas.v5n3p69

The financial support provided by the Research Department of University of Tehran, Iran.

\begin{abstract}
This study applied a non-parametric method to analyze the efficiency of farmers, discriminate efficient farmers from inefficient ones and to identify wasteful uses of energy in order to optimize the energy inputs for broiler production. Data were collected from 44 broiler farms in six villages in Yazd province (Iran) by using a face-to-face questionnaire performed in January- February 2010 period. The data were collected from 44 broiler farms in six villages from Yazd province, Iran. Average capacity of surveyed farms was 18142 birds. Maximum, minimum and average meat production of farms was 2000,3000 and $2601 \mathrm{~kg}(1000 \mathrm{bird})^{-1}$, respectively. Total energy used in various operations during broiler production was $186885.87 \mathrm{MJ}(1000 \mathrm{bird})^{-1}$. We determined TE (Technical Efficiency), PTE (Pure Technical Efficiency) and SE (Scale Efficiency) of energy use in broiler farms using Data Envelopment Analysis (DEA). Two basic DEA models (CCR and BCC) were used to measure the TEs of the farmers based on five energy inputs and two outputs. The CCR and BCC models indicated 10 and 16 farmers were efficient, respectively. The average values of TE, PTE and SE of farmers were found to be 0.90 , 0.93 and 0.96 , respectively. The results also revealed that about $11 \%$ of the total input resources could be saved if the farmers follow the input package recommended by the DEA.
\end{abstract}

Keywords: Broiler, Data envelopment analysis, Energy savings, Management, Technical efficiency

\section{Introduction}

Energy, being the capacity to do work, is at the heart of all human activities, especially those concerning the production of goods and services (Canakci and Akinci, 2006). Energy is used in almost all facets of living and in all countries, and makes possible the existence of ecosystems, human civilizations and life itself. Different regions and societies adapt to their environments and determine their own energy resources and energy uses. The standards of life achieved in countries are often a function of energy related factors. On the other hand, energy can exist in many forms, and can be converted from one form to another with energy conversion technologies. We use energy carriers, produced from energy sources, in all aspects of living (Toklu et al. 2010). Nowadays hens are inter-breaded, so chicks in a short period reach to desirable weight. The intensity of energy use on broiler farms is high and studies on input-output energy pattern on broiler farms are very important. Efficient use 
of agricultural product energies helps to achieve increased production and productivity and contributes to the profitability and competitiveness of agriculture sustainability in rural living (Singh et al., 2002). Some researchers studied on energy consumption in broiler production by parametric methods. Jekayinfa et al. (2007) studied energy audit of poultry processing plants in southwestern Nigeria. Atilgan and Hayati (2006) analyzed cultural energy on broilers reared in different capacity poultry houses of Turkey. Results of their study showed that increasing capacity of housings decreases cultural energy input up to certain capacity and indicated that increasing housing capacity without interfering with performance could be a means for energy conservation in sustainable agriculture. Also a number of studies have been carried out on efficiency in crop and livestock farms (Latruffe et al., 2004) and other livestock production such as poultry egg (Binuomote et al., 2008; Yusef and Malomo, 2007; Ojo, 2003), dairy farm (Balcombe et al., 2006; Bravo-Ureta and Rieger, 1990), and fish farm (Inoni, 2007; Ekunwe and Emokaro, 2009).

This study presents an application of data envelopment analysis (DEA) to discriminate efficient farmers from inefficient ones. DEA is a nonparametric method in operations research and economics for the estimation of production frontiers (Charnes et al., 1994). It is used to empirically measure productive efficiency of decision making units (DMUs). DEA develops a function whose form is determined by the most efficient farmers. This method differs from the Ordinary Least Squares (OLS) statistical technique that bases comparisons relative to an average farmer. Since the work by Charnes et al. (1978), DEA can be a powerful tool when used wisely. A few of the characteristics that make it powerful are:

- DEA can handle multiple input and multiple output models.

- It doesn't require an assumption of a functional form relating inputs to outputs.

- DMUs are directly compared against a peer or combination of peers.

- Inputs and outputs can have very different units. For example, $X_{1}$ could be in units of lives saved and $\mathrm{X}_{2}$ could be in units of dollars without requiring an a priori tradeoff between the two.

DEA has been used in energy, economic and environmental modeling in recent studies. Begum et al. (2010) calculated technical, allocative and economic efficiencies of commercial poultry farms in Bangladesh using the DEA approach under CRS and VRS specification. Zhou et al. (2008) presented a literature survey on the application of DEA to E\&E studies, beginning with an introduction to the most widely used DEA techniques, which was followed by a classification of 100 publications in this field. This survey of DEA in E\&E studies would be useful to researchers entering this exciting field. In the study of Chauhan et al. (2006) in the alluvial zone in the state of west Bengal in India, DEA approach was applied to determine the efficiencies of growers with regard to energy use in rice production activities. The results revealed that, on an average, about $11.6 \%$ of the total input energy could be saved if the growers follow the input package recommended by their study.

Recently, Omid et al. (2011) investigated the degree of efficiency of selected greenhouse producers in Iran and described the process of benchmarking energy inputs and output yield by applying DEA technique. Here the same methodology is adopted for selected broiler farms. The objectives were to specify energy use for broiler production, to segregate efficient farmers from inefficient ones, and to identify wasteful uses of energy inputs for broiler production in Yazd province.

\section{Materials and methods}

\subsection{Case study and data collection}

In this study, the data were collected from 44 broiler farms in six villages from Yazd province, Iran. Share of this province in broiler farms within Iran was $5 \%$ for 2009 production year, with 577 broiler farms. The production of broiler was about 1988 tons/year in Yazd province (Anonymous, 2009). Data were collected from the farmers by using a face-to-face questionnaire performed in January- February 2010 period. Farms were randomly chosen from the villages in the area of study. The sample size was determined using Neyman method and was calculated as 44 farms (Yamane, 1967).

The inputs included hours or amount of different energy sources such as chick, diesel fuel, feeds, electricity, equipment and human labor, and output energy included broiler and manure transformed to energy term by appropriate energy equivalents. Input values were converted to energy equivalents by multiplying the quantity per 1000bird.

\subsection{Correlation analysis}

Correlation analysis is a family of statistical tests to determine mathematically whether there are trends or relationships between two or more sets of data from the same list of items or individuals (for example, 
equipment and fuel consumption of farms). The tests provide a statistical yes or no as to whether a significant relationship or correlation exists between the variables (Childress, 1985).

\subsection{DEA models}

Data Envelopment Analysis (DEA) is becoming an increasingly popular management tool and is commonly used to evaluate the efficiency of a number of producers. A typical statistical approach is characterized as a central tendency approach and it evaluates producers relative to an average producer. In contrast, DEA is an extreme point method and compares each producer with only the "best" producers. There are two kinds of DEA models included: CCR and BCC models (Charnes et al., 1978). The CCR model is built on the assumption of constant returns to scale (CRS) of activities, but the BCC model is built on the assumption of variable returns to scale (VRS) of activities. Efficiency by DEA is defined in three different forms: overall technical efficiency $\left(\mathrm{TE}_{\mathrm{CCR}}\right)$, pure technical efficiency $\left(\mathrm{TE}_{\mathrm{BCC}}\right)$ and scale efficiency (SE).

\subsection{Technical efficiency}

Technical efficiency (TE) can be calculated by the ratio of sum of weighted outputs to sum of weighted inputs (Cooper et al., 2006):

$$
\theta=\frac{\sum_{p=1}^{P} u_{p} y_{p, j}}{\sum_{q=1}^{Q} v_{q} x_{q, j}}
$$

where ' $\mathrm{x}$ ' and ' $\mathrm{y}$ ' are inputs and outputs, ' $v$ ' and ' $u$ ' are input and output weights, respectively, ' $\mathrm{q}$ ' is the number of inputs $(q=1,2, \ldots, Q)$; ' $p$ ' is the number of outputs $(p=1,2, \ldots, P)$; and ' $j$ ' represents $j{ }^{\text {th }}$ DMU.

The CCR model was initially proposed by Charnes et al. (1978). The CCR model is indicated in Eq. (2):

$\min \theta$

subject to:

$$
\begin{gathered}
\sum_{j=1}^{J} \lambda_{j} y_{p, j} \geq y_{p, 0} \\
\sum_{j=1}^{J} \lambda_{j} x_{q, j} \leq \theta \cdot x_{q, 0} \\
\lambda_{j} \geq 0
\end{gathered}
$$

where $\lambda_{j}$ is a vector of $\mathrm{j}$ elements representing the influence of each farmer in determining the technical efficiency of the DMU under study, and $\theta$ is the technical efficiency ( $\left.\mathrm{TE}_{\mathrm{CCR}}\right)$.

\subsection{Pure technical efficiency}

Pure technical efficiency is technical efficiency of BCC model. The BCC model was initially proposed by Banker, Charnes and Cooper (1984). The function of input-oriented BCC model for evaluating of efficiency of $\mathrm{DMU}_{\mathrm{j}}\left(\mathrm{TE}_{\mathrm{BCC}}\right)$ is like CCR model, but in this model the equation $\sum_{j=1}^{J} \lambda_{j}=1$ is a convexity constraint, which specifies the VRS framework (Mostafa, 2009).

Without this convexity constraint, the BCC model will be a CCR model (Eq. 2) describing a CRS situation.

\subsection{Scale efficiency}

Based on the CCR and BCC scores, scale efficiency defined by (Cooper et al., 2006):

$$
S E=\frac{T E_{C C R}}{T E_{B C C}}
$$

In other words decomposition of Eq. (3) can be defined by:

$$
T E_{C C R}=T E_{B C C} \times S E
$$

This decomposition, which is unique, depicts the sources of inefficiency, i.e., whether it is caused by inefficient operation (PTE) or by disadvantageous conditions displayed by the scale efficiency (SE) or by both. If the scale efficiency is less than 1, the DMU will be operating either at decreasing returns to scale (DRS) if a proportional increase of all input levels produces a less-than-proportional increase in output levels or increasing return to 
scale (IRS) at the converse case. This implies that resources may be transferred from DMUs operating at DRS to scale to those operating at IRS to increase average productivity at both sets of DMUs (Boussofiane et al., 1992).

By solving of CCR and BCC models, the weights of remaining inputs (diesel fuel, feed, electricity, equipment and human labor ) and output (broiler and manure) would be calculated so the maximum value of $\theta$ is calculated. Because of the low contribution of chick energy in CCR and BCC models it was omitted from these models. In this study we used DEA-solver software to calculate CRS and VRS with radial distances to the efficient frontier and determine the amount of energy loss and energy savings of inefficient farmers.

\section{Results and discussion}

\subsection{Energy inputs and correlation between energy inputs of broiler production}

Average capacity of surveyed farms was 18142 birds. Minimum, maximum and average meat production of farms was 2000, 3000 and $2601 \mathrm{~kg}(1000 \mathrm{bird})^{-1}$, respectively. Total energy used in various operations during broiler production was $186885.87 \mathrm{MJ}^{(1000 \mathrm{bird})^{-1} \text {. }}$

Data in Table 2 indicates the correlation between energy inputs used in broiler production in the studied area. The value of a correlation coefficient can vary from minus one to plus one. A minus one indicates a perfect negative correlation, while a plus one indicates a perfect positive correlation. A correlation of zero means there is no relationship between the two variables. When there is a negative correlation between two variables, as the value of one variable increases, the value of the other variable decreases, and vise versa. In other words, for a negative correlation, the variables work opposite each other. When there is a positive correlation between two variables, as the value of one variable increases, the value of the other variable also increases. The variables move together. It was found, the highest value of correlation was between labor and equipment energies as 0.54 , indicated as the value of labor energy or equipment energy increases, the value of the equipment energy or labor energy increases.

\subsection{DEA results}

In this study, we used CCR and BCC models to evaluate technical, pure technical and scale efficiencies (TE, PTE and SE, respectively) of broiler farms. The results of CCR and BCC models are shown in Table 3 and Fig 1. Based on CCR results, this study shows that only 10 farmers were relatively efficient and the remaining 34 were inefficient, i.e. their efficiency scores were below 1. But from the results of BCC model, we found 16 farmers (out of total 44 farmers) were efficient, meaning they have an efficiency score of 1 (Table 3). Other farmers who have efficiency score less than one, are inefficient in energy use. The technical, pure, scale efficiencies of the remaining 28 inefficient farmers is shown in Fig. 1. The average values of the PTE, TE and SE are summarized in Table 3. The average values (for all 44 farmers considered) of PTE, TE and SE were found to be 0.9314, 0.8954 and 0.9606 , respectively. The mean value of PTE for the inefficient farmers (0.8922) indicates that there is ample scope for improving their operating practices to enhance their energy use efficiency. In a similar study, PTE, TE and SE for rice production were reported to be $0.9249,0.7720$ and 0.8302 , respectively (Chauhan et al., 2006) and $0.972,0.879$ and 0.900 for greenhouse cucumber, respectively (Omid et al., 2011).

It is evident from Fig. 2 that the majority of inefficient farmers were in the SE range of 0.9-0.99. The average of SEs was low. Identifying efficient operating practices and their dissemination will help to improve efficiency not only in the case of inefficient farmers but also for some relatively efficient ones. By raising the meat yield and by decreasing energy inputs consumption the inefficient farmers can increase their energy efficiency. The efficient farmers obviously follow good operating practices. However, among the efficient farmers, some (farms: 1, 19, $34,36-38,40,41,43,44)$ show better operating practices than others. Therefore, discrimination is required to be made among the efficient farmers while seeking the best operating practices. These efficient farms can be selected by inefficient DMUs as best practice DMUs, making them a composite DMU instead of using a single DMU as a benchmark. The farm1 appears nineteen times in the reference set of inefficient DMUs. This places farm 1 closest to the input and output levels of most of the inefficient DMUs but uses fewer inputs. The latest column of table 3 indicated results of return to scale. The analysis shows that DMUs numbered 1, 3-7, 10, 17-19, $23,25,28-29,31,34,36-38,40-44$ that are efficient under the CRS model are both technically and scale efficient (Table 3). The RTS indicated that all efficient farms (based on pure technical efficiency) were operating at CRS and for inefficient farms technological change is required for considerable changes in yield.

The PTE score of a farmer that is less than one indicates that, at present, he/she is using more energy than required from the different sources (Chauhan et al., 2006). Therefore, it is desired to suggest realistic levels of energy to be used from each source for every inefficient farmer in order to avert wastage of energy without reducing the yield level. Table A1 in Appendix A gives, for each inefficient farmer, the PTE, the actual energy 
use (MJ (1000bird) $)^{-1}$ ) and the recommended projection energy use (MJ (1000bird $)^{-1}$ ) for each input and the percent saving in total energy use.

Table 4 summarizes the information available in Table A1. It gives the average energy spent and targeted (MJ $\left.(1000 \mathrm{bird})^{-1}\right)$, possible energy savings and percent contribution of each energy source in the total energy savings. We note from Table A1 that the possible overall energy saving is $11 \%$. Fig. 3 shows the share of the various sources in the total input energy savings. It is evident from Table 4 and Fig. 3 that the maximum contribution to the total energy savings is $58 \%$ from diesel fuel, followed by feeds $(26 \%)$ and electricity (16\%). Electricity power was used in automatic feeding and lighting equipment's. Artificial lighting is the way to raise the production of chickens. If the housing is lit in the cooler hours before sunrise or after sunset, the chickens are able to eat more. However, day length must not be increased during the growing period of the young chicks until just before they start laying. Other energy inputs (equipment and labor) only included under $1 \%$ of energy saving. Chauhan et al. (2006) reported a total input energy of $11.6 \%$ could be saved for rice production and the maximum contribution to the total energy savings was 33\% from fertilizers. In the study of Omid et al. (2011) on an average, the total input energy could be reduced by $8.5 \%$ without reducing the cucumber yield from its present. Diesel fuel carries relatively higher weights in the distribution of the virtual inputs for truly efficient producers by $76.7 \%$.

Diesel fuel contributes $58 \%$ of the total input energy saving for inefficient farmers. The majority of the surveyed farms consumed diesel fuel to warm their rooms. In order to improve the farms environment as well as reduction of diesel fuel consumption, it is strongly suggested that the heating system efficiency is raised or replaced with alternative sources of energy such as natural gas, solar energy, etc. Feeds contributes $26 \%$ of the total input energy saving. In most cases of surveyed farms in this study, there are given free access to food and the birds are allowed to consume as much food as they wish. Broilers usually consume just enough food to meet their nutrient requirements. This control of intake is based primarily on the amount of energy in the diet.

\section{Conclusions}

This paper describes the application of DEA to the study for improving the energy use in the broiler production in the central region of Iran. This technique allows the determination of the best practice farms and can also provide helpful insights for farm management. DEA has helped in segregating efficient farmers from inefficient farmers. It has also helped in finding the wasteful uses of energy by inefficient farmers, ranking efficient farmers by using the CCR and BCC models and ranking energy sources by using technical, pure technical and scale efficiency. Broiler production consumed a total energy of $186885.87 \mathrm{MJ}$ (1000bird) ${ }^{-1}$, which was mainly due to diesel fuel. The limited oil fuel sources implies that policy makers must determine the best regional plans for management and raisin inputs productivity in boiler production. On an average, the total input energy could be reduced by $11 \%$ without reducing the output energy from its present level by adopting the recommendations based on this study. Diesel fuel, feed and electricity had relatively higher weights in the distribution of total input energy saving for inefficient farmers.

Based on our findings, modern and well established scientific practices should be used to obtain higher technical efficiency from broiler farming like:

1) Inefficient farmers should pay more attention towards diesel, feeds and electricity sources to improve their energy productivity.

2) It is important to have a good idea of how much feeds are eaten, in particular the amount of feeds needed per $\mathrm{kg}$ of meat (feeds conversion).

3) There is a need for capacity training of poultry farmers and processors to enable them cope with the challenges of modern poultry farming and commercialization of the poultry sub-sector in the studied region.

4) Purchase of improved strain of one day old healthy broiler type chicks from a reputed hatchery.

\section{Appendix A}

Table A1 gives, for each inefficient farmer, the pure technical efficiency (PTE), the actual energy use, (MJ $\left(1000 \mathrm{bird}^{-1}\right)$, the recommended projection energy use $\left(\mathrm{MJ}(1000 \mathrm{bird})^{-1}\right)$ for each input and the percent saving in total energy use. The complete scores for all DMUs are presented in Table 3.

\section{Acknowledgment}

The authors appreciate the support from the Agri-Jihad Organization of Yazd province, Iran. The financial support provided by University of Tehran, Iran, is duly acknowledged. 


\section{References}

Alrwis, K.N., Francis, E. (2003). Technical efficiency of broiler farms in the central region of Saudi Aradia: Stochastic Frontier Approach. Research bulletin, 5-34.

Anonymous. 2009. Annual Agricultural Statistics. Ministry of Jihad-e-Agriculture of Iran; http://www.maj.ir.

Atilgan, A., Hayati, K. (2006). Cultural energy analysis on broilers reared in different capacity poultry houses. Italian Journal of Animal Science, 393-400.

Balcombea, K., Frasera, I., Kim, J. H. (2006). Estimating technical efficiency of Australian dairy farms using alternative frontier methodologies. Applied Economics, 38, 2221-2236.

Banker, R.D., Charnes, A., Cooper, W.W. (1984). Some models for estimating technical and scale inefficiencies in data envelopment analysis. Management Science, 30, 1078-1092.

Begum, I.A., Buysse, J., Alam, M.J., Van Huylenbroeck, G. (2010). Technical, allocative and economic efficiency of commercial poultry farms in Bangladesh. Worlds Poultry Science Journal, 66, 465-476.

Berg, M. J., Tymoczkyo, L. J. \& Stryer, L. (2002). Biochemistry 5th edition: New York: W.H.Freeman.

Binuomote, S.O., Ajetomobi, J.O., Ajao, A.O. (2008). Technical efficiency of egg production in Osun State. International Journal of Poultry Science, 7(12), 1227-1231.

Boussofiane, A., Dyson, R.G., Thanassoulis, E. (1992). Applied data envelopment analysis. European Journal of Operation Research, 52, 1-15.

Bravo-Ureta, B.E., Rieger, L. (1990). Alternative production frontier methodologies and dairy farm efficiencies. Journal of Agricultural Economics, 14, 215-226.

Canakci, M. \& Akinci, I. (2006). Energy use pattern analyses of greenhouse vegetable production. Energy, 31, 1243-1256.

Celik, L.O. (2003). Effects of dietary supplemental l-carnitine and ascorbic acid on performance, carcass composition and plasma lcarnitine concentration of broiler chicks reared under different temperature. Archives of Animal Nutrition, 27-38.

Charnes, A., Cooper, W.W., Lewin, A. \& Seiford, L. (1994). Data envelopment analysis: theory, methodology and application., Kluwer Academic Publishers Boston, MA.

Charnes, A., Cooper, W.W., Rhodes, E. (1978). Measuring the efficiency of decision making units. European Journal of Operational Research, 2, 429-441.

Chauhan, N. S. Mohapatra, P.K.J., Pandey, K.P. (2006). Improving energy productivity in paddy production through benchmarking: an application of data envelopment analysis. Energy Conversion and Management, 47, 1063-1085.

Childress, W.M. (1985). Correlation analysis; a statistical test for relationships between two sets of data. Creative Computing 11, No. 9 : September, pp. 96.

Cooper, W.W., Seiford, L.M. \& Tone, K. (2006). Introduction to DEA and its uses with DEA-Solver software and references, Springer, New York.

Ekunwe, P. A., Emokaro, C.O. (2009). Technical efficiency of catfish farmers in Kaduna, Nigeria. Journal of Appleid Science Research, 5(7), 802-805.

Heidari, M.D., Omid, M. (2011). Energy use patterns and econometric models of major greenhouse vegetable productions in Iran. Energy, 36, 220-225.

Inoni, O.E. (2007). Allocative efficiency in Pond fish production in Delta state, Nigeria: A production function approach. Agricultura tropica et subtropica, 40(4), 127-134.

Jekayinfa, O., Simeon. (2007). Energetic analysis of poultry processing operations. Leonardo Journal of Sciences, 77-92.

Kitani, O. (1999). Energy and Biomass Engineering. In: CIGR Handbook of Agricultural Engineering Vol. V, ASAE Publication, St. Joseph, MI, pp. 330.

Kittle, A.P. (1993). Alternate daily cover materials and subtitle, the Selection technique Rusmar. Incorporated West Chester, PA.

Kizilaslan, H. (2009). Input-output energy analysis of cherries production in Tokat Province of Turkey. Applied Energy, 86, 1354-1358.

Latruffe, L., Balcombe, K., Davidova, S., Zawalinska K. (2004). Determinants of technical efficiency of crop and livestock farms in Poland. Applied Economics, 36, 1255-1263.

Mostafa, M.M. (2009). Modeling the efficiency of top Arab banks: A DEA-neural network approach. Expert Systems with Applications, 36, 309-320. 
Najafi anari, S., Khademolhoseini, N., Jazayeri, K., Mirzade, K. (2008). Assessing of energy efficiency on broiler farm in the Ahvaze zone. 5th National Conference on Agriculture Machinery and Mechanization, August 26-27, Iran: Mashad (in Farsi).

Ojo, S.O. (2003). Productivity and technical efficiency of poultry egg production in Nigeria. International Journal of Poultry Science, 2(6), 459-464.

Omid, M., Ghojabeige, F., Delshad, M., Ahmadi, H. (2011). Energy use pattern and benchmarking of selected greenhouses in Iran using data envelopment analysis. Energy Conversion and Management, 52, $153-162$.

Sainz, R.D. (2003). Livestock-environment initiative fossil fuels component: Framework for calculating fossil fuel use in livestock systems, pp. 20.

Singh, H., Mishra, D., Nahar, N.M. (2002). Energy use pattern in production agriculture of typical village in arid zone, India-part-I. Energy Conversion and Management, 43, 2275-2286.

Toklu, E., Guney, M.S., Isik, M., Comakli, O. \& Kaygusuz, K. (2010). Energy production, consumption, policies and recent developments in Turkey. Renewable and Sustainable Energy Reviews, 14, 1172-1186.

Yamane, T. (19670. Elementary sampling theory. New Jersey, USA : Prentice Hall Englewood Cliffs.

Yusef, S.A., Malomo, O. (2007). Technical efficiency of poultry egg production in Ogun state: a data envelopment analysis (DEA) approach. International Journal of Poultry Science, 6(9), 622-629.

Zhou, P., Ang, B.W., Poh, K.L. (2008). A survey of data envelopment analysis in energy and environmental studies. European Journal of Operational Research, 189, 1-18.

Table 1. Energy equivalents of inputs and outputs in broiler production

\begin{tabular}{|c|c|c|c|}
\hline Inputs & Unit & 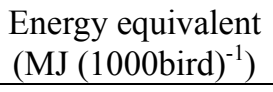 & Reference \\
\hline \multicolumn{4}{|l|}{ A. Inputs } \\
\hline Chick & $\mathrm{kg}$ & 10.33 & (Najafi et al., 2008) \\
\hline Human labor & $\mathrm{h}$ & 1.96 & (Heidari and Omid, 2011) \\
\hline \multicolumn{4}{|l|}{ Machinery } \\
\hline (a) Electric motor & $\mathrm{kg}$ & 64.8 & (Chauhan et al., 2006) \\
\hline (b) Steel & $\mathrm{kg}$ & 62.7 & (Chauhan et al., 2006) \\
\hline (c) Polyethylene & $\mathrm{kg}$ & 46.3 & (Kittle, 1993) \\
\hline Diesel fuel & 1 & 47.8 & (Kitani, 1999) \\
\hline \multicolumn{4}{|l|}{ Feeds } \\
\hline (a) Maize & $\mathrm{kg}$ & 7.9 & (Atilgan and Hayati 2006) \\
\hline (b) Soybean meal & $\mathrm{kg}$ & 12.06 & (Atilgan and Hayati, 2006) \\
\hline (c) Di calcium Phosphate & $\mathrm{kg}$ & 10 & (Alrwis and Francis, 2003) \\
\hline (d) Fatty acid & $\mathrm{kg}$ & 9 & ( Berg, 2002) \\
\hline Minerals and vitamins & $\mathrm{m}^{3}$ & 1.59 & ( Sainz, 2003) \\
\hline Electricity & $\mathrm{kWh}$ & 3.6 & (Heidari and Omid, 2011) \\
\hline \multicolumn{4}{|l|}{ B. Outputs } \\
\hline Broiler & $\mathrm{kg}$ & 10.33 & (Celik, 2003) \\
\hline Manure & $\mathrm{kg}$ & 0.3 & (Kizilaslan, 2009) \\
\hline
\end{tabular}

Table 2. Correlation between energy sources in broiler production

\begin{tabular}{|c|c|c|c|c|c|c|c|}
\hline & Chick & Fuel & Feed & Electricity & Equipment & Labor & $\begin{array}{l}\text { Output } \\
\text { Energy }\end{array}$ \\
\hline Chick & 1.00 & & & & & & \\
\hline Fuel & 0.06 & 1.00 & & & & & \\
\hline Feed & 0.13 & 0.04 & 1.00 & & & & \\
\hline Electricity & -0.08 & 0.07 & -0.05 & 1.00 & & & \\
\hline Equipment & -0.41 & 0.00 & -0.04 & 0.42 & 1.00 & & \\
\hline Labor & -0.17 & -0.04 & 0.05 & 0.45 & 0.54 & 1.00 & \\
\hline Output Energy & 0.15 & 0.32 & 0.34 & 0.11 & -0.06 & -0.13 & 1.00 \\
\hline
\end{tabular}


Table 3. Efficiency scores of farms based on CCR and BCC models

\begin{tabular}{|c|c|c|c|c|c|}
\hline DMU & $\mathrm{TE}_{\mathrm{CCR}}$ & $\mathrm{E}_{\mathrm{BCC}}$ & SE & $\begin{array}{c}\text { Frequency in } \\
\text { referent set }\end{array}$ & RTS \\
\hline 1 & 1.00 & 1.00 & 1.00 & 19 & Constant \\
\hline 2 & 0.98 & 1.00 & 0.98 & 0 & Increasing \\
\hline 3 & 0.85 & 0.88 & 0.97 & 0 & Constant \\
\hline 4 & 0.85 & 0.87 & 0.98 & 0 & Constant \\
\hline 5 & 0.86 & 0.88 & 0.97 & 0 & Constant \\
\hline 6 & 0.89 & 0.90 & 1.00 & 0 & Constant \\
\hline 7 & 0.97 & 0.97 & 1.00 & 0 & Constant \\
\hline 8 & 0.88 & 0.89 & 0.99 & 0 & Decreasing \\
\hline 9 & 0.91 & 0.94 & 0.97 & 0 & Decreasing \\
\hline 10 & 0.75 & 0.85 & 0.88 & 0 & Constant \\
\hline 11 & 0.98 & 1.00 & 0.98 & 0 & Decreasing \\
\hline 12 & 0.79 & 0.83 & 0.96 & 0 & Decreasing \\
\hline 13 & 0.75 & 0.91 & 0.82 & 0 & Increasing \\
\hline 14 & 0.96 & 0.98 & 0.98 & 0 & Increasing \\
\hline 15 & 0.85 & 0.90 & 0.95 & 0 & Increasing \\
\hline 16 & 0.81 & 0.87 & 0.93 & 0 & Increasing \\
\hline 17 & 0.92 & 0.94 & 0.99 & 0 & Constant \\
\hline 18 & 0.79 & 0.85 & 0.93 & 0 & Constant \\
\hline 19 & 1.00 & 1.00 & 1.00 & 2 & Constant \\
\hline 20 & 0.92 & 1.00 & 0.92 & 0 & Decreasing \\
\hline 21 & 0.84 & 0.84 & 1.00 & 0 & Decreasing \\
\hline 22 & 0.95 & 0.95 & 1.00 & 0 & Decreasing \\
\hline 23 & 0.73 & 0.74 & 0.98 & 0 & Constant \\
\hline 24 & 0.67 & 0.88 & 0.76 & 0 & Increasing \\
\hline 25 & 0.88 & 0.91 & 0.96 & 0 & Constant \\
\hline 26 & 0.97 & 1.00 & 0.97 & 0 & Decreasing \\
\hline 27 & 0.82 & 0.84 & 0.97 & 0 & Increasing \\
\hline 28 & 0.83 & 0.85 & 0.98 & 0 & Constant \\
\hline 29 & 0.92 & 0.97 & 0.95 & 0 & Constant \\
\hline 30 & 0.83 & 0.95 & 0.87 & 0 & Increasing \\
\hline 31 & 0.79 & 0.80 & 0.98 & 0 & Constant \\
\hline 32 & 0.78 & 0.86 & 0.91 & 0 & Decreasing \\
\hline 33 & 0.86 & 1.00 & 0.86 & 0 & Decreasing \\
\hline 34 & 1.00 & 1.00 & 1.00 & 4 & Constant \\
\hline 35 & 0.95 & 0.95 & 0.99 & 0 & Decreasing \\
\hline 36 & 1.00 & 1.00 & 1.00 & 1 & Constant \\
\hline 37 & 1.00 & 1.00 & 1.00 & 1 & Constant \\
\hline 38 & 1.00 & 1.00 & 1.00 & 12 & Constant \\
\hline 39 & 0.94 & 1.00 & 0.94 & 0 & Increasing \\
\hline 40 & 1.00 & 1.00 & 1.00 & 1 & Constant \\
\hline 41 & 1.00 & 1.00 & 1.00 & 2 & Constant \\
\hline 42 & 0.94 & 0.98 & 0.96 & 0 & Constant \\
\hline 43 & 1.00 & 1.00 & 1.00 & 1 & Constant \\
\hline 44 & 1.00 & 1.00 & 1.00 & 1 & Constant \\
\hline Mean & 0.90 & 0.93 & 0.96 & & \\
\hline STD & 0.09 & 0.07 & 0.05 & & \\
\hline
\end{tabular}


Table 4. Energy saving (MJ/1000bird) from different sources

\begin{tabular}{lllll}
\hline Input & $\begin{array}{l}\text { Present use } \\
\left.(\text { MJ.(1000bird) })^{-1}\right)\end{array}$ & $\begin{array}{l}\text { Target use } \\
\left.(\text { MJ.(1000bird })^{-1}\right)\end{array}$ & $\begin{array}{l}\text { Energy saving } \\
\left.(\text { MJ.(1000bird })^{-1}\right)\end{array}$ & $\begin{array}{l}\text { Contribution of input } \\
\text { to savings, \% }\end{array}$ \\
\hline Fuel Energy & 110632.79 & 96073.32 & 14559.48 & 57.58 \\
Feed & 59311.40 & 52717.23 & 6594.17 & 26.08 \\
Electricity & 16085.73 & 12023.67 & 4062.05 & 16.07 \\
$\begin{array}{l}\text { Equipment } \\
\text { Labor }\end{array}$ & 196.06 & 159.55 & 36.52 & 0.14 \\
\hline $\begin{array}{l}\text { Total input } \\
\text { energy }\end{array}$ & 127.93 & 95.48 & 32.46 & 0.13 \\
\hline
\end{tabular}

Table A. The percentages in energy savings of inefficient farmers (based on BCC Mode1)

\begin{tabular}{|c|c|c|c|c|c|c|c|c|c|c|c|c|}
\hline \multirow{2}{*}{$\mathrm{DMU}$} & \multirow{2}{*}{ PTE } & \multicolumn{5}{|c|}{ Actual Energy use MJ/1000bird } & \multicolumn{5}{|c|}{ Projection Energy use MJ/1000bird } & \multirow{2}{*}{ Saving $\%$} \\
\hline & & Fuel & Feed & Electricity & Equip & Labor & Fuel & Feed & Electricity & Equip & Labor & \\
\hline 3 & 0.88 & 150841.5 & 53868.0 & 15944.5 & 210.1 & 137.4 & 132174.8 & 47201.8 & 13971.4 & 184.1 & 120.4 & 12.4 \\
\hline 4 & 0.87 & 168169.1 & 54063.9 & 16732.7 & 221.2 & 125.4 & 145711.2 & 46844.0 & 14498.2 & 191.7 & 108.7 & 13.4 \\
\hline 5 & 0.88 & 136571.4 & 53098.5 & 11213.7 & 232.3 & 129.4 & 120710.7 & 46931.9 & 9911.4 & 205.3 & 114.3 & 11.6 \\
\hline 6 & 0.90 & 166042.1 & 68043.8 & 10637.1 & 254.4 & 113.9 & 149019.5 & 61068.0 & 9546.6 & 228.3 & 102.2 & 10.3 \\
\hline 7 & 0.97 & 134228.7 & 54155.5 & 10134.6 & 154.8 & 126.7 & 130614.4 & 52697.3 & 9861.7 & 150.7 & 123.3 & 2.7 \\
\hline 8 & 0.89 & 144323.7 & 58552.2 & 13947.9 & 165.9 & 122.1 & 128867.6 & 52281.6 & 12454.2 & 148.1 & 109.1 & 10.7 \\
\hline 9 & 0.94 & 96985.5 & 60894.3 & 15299.1 & 204.6 & 176.7 & 90876.8 & 57058.8 & 14335.5 & 191.7 & 165.6 & 6.3 \\
\hline 10 & 0.85 & 142828.7 & 69749.4 & 20219.9 & 160.4 & 171.8 & 121112.3 & 59144.4 & 17145.5 & 136.0 & 145.7 & 15.2 \\
\hline 12 & 0.83 & 141049.2 & 61815.7 & 16566.0 & 259.9 & 172.9 & 116897.9 & 51231.3 & 13729.5 & 215.4 & 143.3 & 17.1 \\
\hline 13 & 0.91 & 89625.0 & 56112.5 & 14379.7 & 237.8 & 209.1 & 81348.6 & 50930.8 & 13051.8 & 215.8 & 189.8 & 9.2 \\
\hline 14 & 0.98 & 66184.6 & 58011.7 & 13325.6 & 248.9 & 171.3 & 64810.0 & 56806.8 & 13048.9 & 243.7 & 167.7 & 2.1 \\
\hline 15 & 0.90 & 73538.5 & 62155.4 & 15095.4 & 254.4 & 177.9 & 66309.7 & 56045.6 & 13611.6 & 229.4 & 160.4 & 9.8 \\
\hline 16 & 0.87 & 93521.7 & 59723.2 & 11974.5 & 243.3 & 119.3 & 81545.0 & 52074.8 & 10441.0 & 212.2 & 104.0 & 12.8 \\
\hline 17 & 0.94 & 69275.4 & 58552.2 & 28440.7 & 265.4 & 170.4 & 64928.8 & 54878.5 & 26656.2 & 248.8 & 159.7 & 6.3 \\
\hline 18 & 0.85 & 104366.8 & 70569.4 & 9160.5 & 259.9 & 114.7 & 88343.3 & 59734.9 & 7754.0 & 220.0 & 97.1 & 15.4 \\
\hline 21 & 0.84 & 130174.3 & 52811.8 & 17710.9 & 193.6 & 133.2 & 109640.1 & 44481.0 & 14917.1 & 163.0 & 112.2 & 15.8 \\
\hline 22 & 0.95 & 106274.7 & 58552.2 & 23871.4 & 149.3 & 96.1 & 101082.5 & 55691.5 & 22705.2 & 142.0 & 91.4 & 4.9 \\
\hline 23 & 0.74 & 148711.1 & 62247.5 & 24862.2 & 193.6 & 202.1 & 109765.7 & 45945.7 & 18351.1 & 142.9 & 149.2 & 26.2 \\
\hline 24 & 0.88 & 80296.4 & 63875.1 & 10431.2 & 165.9 & 147.2 & 70825.8 & 56341.3 & 9200.9 & 146.3 & 129.8 & 11.8 \\
\hline 25 & 0.91 & 88989.4 & 58452.5 & 13869.8 & 154.8 & 110.9 & 81042.3 & 53232.5 & 12631.2 & 141.0 & 101.0 & 8.9 \\
\hline 27 & 0.84 & 89625.0 & 60601.5 & 22415.4 & 259.9 & 264.6 & 75181.4 & 50835.2 & 18803.0 & 218.0 & 222.0 & 16.1 \\
\hline 28 & 0.85 & 129891.3 & 58552.2 & 22924.2 & 165.9 & 179.0 & 110352.7 & 49744.6 & 19475.8 & 140.9 & 152.0 & 15.0 \\
\hline 29 & 0.97 & 76790.6 & 57692.6 & 21258.9 & 160.4 & 92.4 & 74449.0 & 55933.3 & 20610.7 & 155.5 & 89.5 & 3.0 \\
\hline 30 & 0.95 & 74223.6 & 58552.2 & 11033.0 & 165.9 & 147.3 & 70744.7 & 55807.8 & 10515.9 & 158.1 & 140.4 & 4.7 \\
\hline 31 & 0.80 & 119004.1 & 55879.7 & 28078.5 & 271.0 & 198.4 & 95775.5 & 44972.4 & 22597.8 & 218.1 & 159.7 & 19.5 \\
\hline 32 & 0.86 & 106537.9 & 75239.1 & 29360.2 & 276.5 & 172.4 & 91437.9 & 64575.2 & 25198.8 & 237.3 & 148.0 & 14.2 \\
\hline 35 & 0.95 & 93177.4 & 59508.9 & 15512.5 & 149.3 & 127.2 & 88972.7 & 56823.6 & 14812.5 & 142.6 & 121.4 & 4.5 \\
\hline 42 & 0.98 & 94770.8 & 53734.5 & 9861.1 & 143.8 & 97.1 & 92808.4 & 52621.9 & 9656.9 & 140.8 & 95.1 & 2.1 \\
\hline
\end{tabular}


$\square$ TEcrs $\square$ TEvrs $\square \mathrm{SE}$

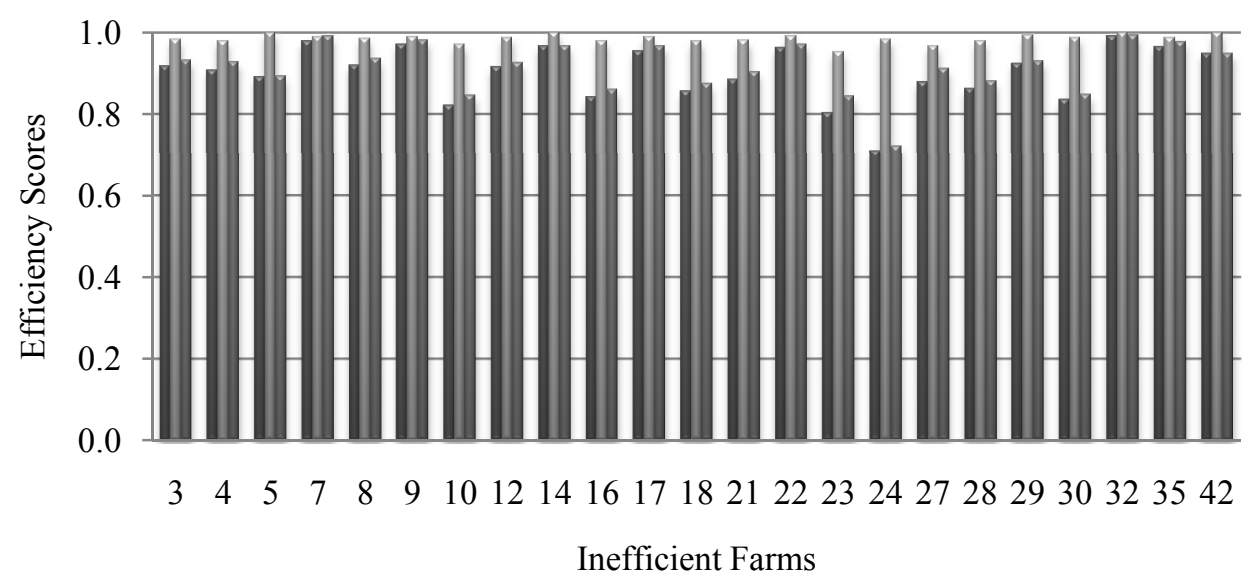

Figure 1. The overall, pure and scale efficiencies of inefficient farms

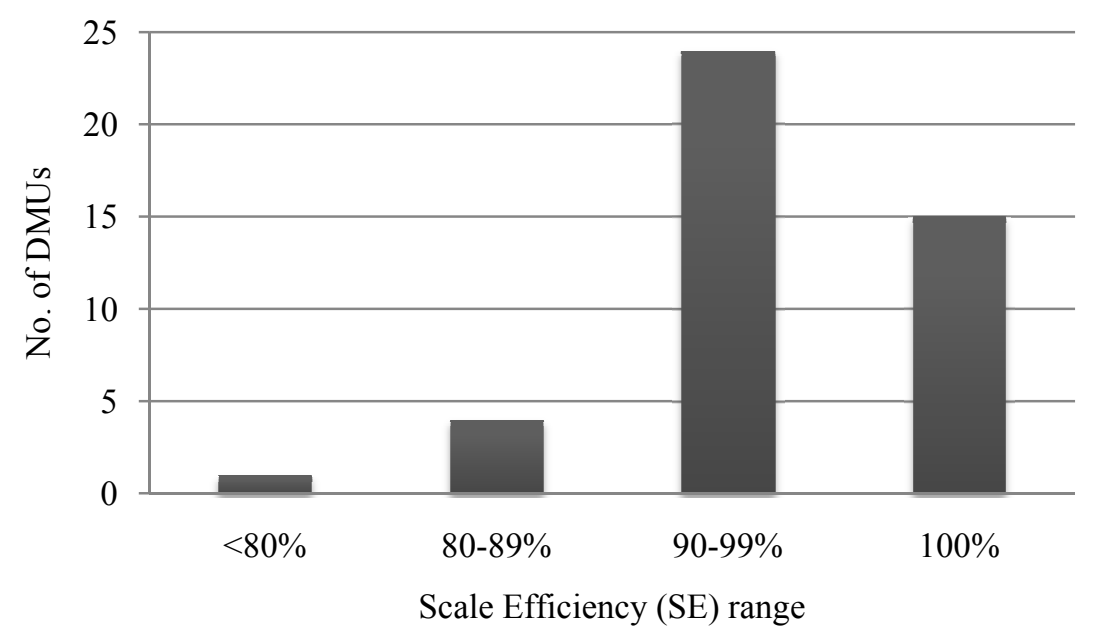

Figure 2. Scale efficiency distribution of farms

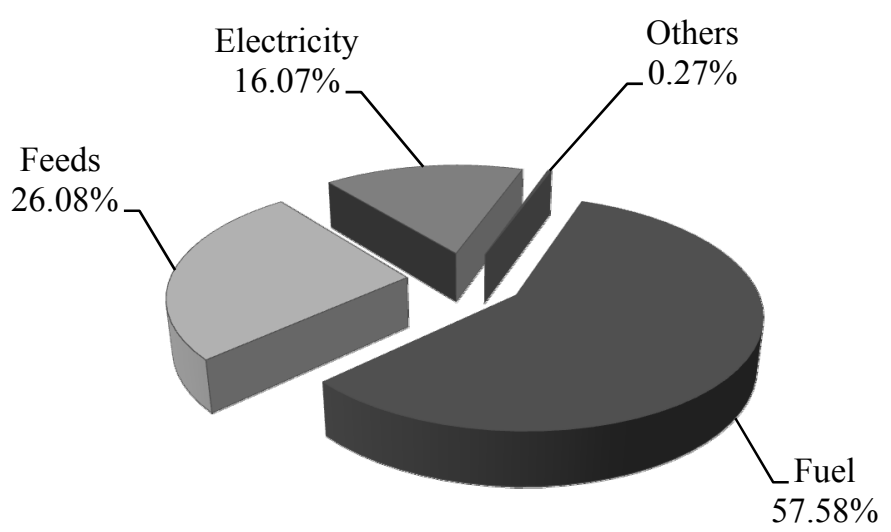

Figure 3. Total potential improvement summary 